\title{
Topographic Targeting Errors in the Retinocollicular Projection and Their Elimination by Selective Ganglion Cell Death
}

\author{
Dennis D. M. O'Leary, James W. Fawcett, and W. Maxwell Cowan \\ The Salk Institute for Biological Studies and The Clayton Foundation for Research-California Division, San Diego, \\ California 92138
}

In adult rats, as in other rodents, the retinocollicular projection is topographically organized in a very precise manner. Experiments involving the use of the retrogradely transported fluorescent dye fast blue as either a short- or long-term marker in neonatal rats indicate that the precision of this retinotopic projection does not arise $a b$ initio, but rather is brought about by the preferential elimination of those ganglion cells whose axons project to topographically inappropriate regions of the colliculus. Such topographic targeting errors have been identified along both the rostrocaudal and mediolateral axes of the colliculus, and their elimination occurs during the period of naturally occurring ganglion cell death, which is completed by about postnatal day 10.

When impulse activity in the retinal ganglion cell axons is blocked by repeated intraocular injections of the sodium channel-blocking agent tetrodotoxin (TTX) throughout the postnatal period of ganglion cell death, the preferential loss of the incorrectly projecting ganglion cells does not occur in the activityblocked eye, although, as reported elsewhere, the overall loss of ganglion cells is comparable to that seen in normal animals. This supports the notion that the mechanism for selecting against incorrectly projecting ganglion cells is based on impulse activity among the competing ganglion cell axons. However, under activity-block conditions, the aberrantly projecting axons appear to retract from the caudal margin of the colliculus.

The death of retinal ganglion cells during development thus seems to serve 2 purposes: It provides for the quantitative matching of the ganglion cell population to the needs of its central projection fields, and, at the same time, it serves to selectively eliminate those cells whose axons project to inappropriate targets or to inappropriate regions within the correct target fields.

During the development of virtually all cell groups in the vertebrate nervous system, there is a period during which about half of the initial population of neurons dies. This phase of "naturally occurring cell death," as it has been termed, usually coincides with the formation of connections between the neuronal population as a whole and its target structures, and is generally thought to be the result of a competition among the

\footnotetext{
Received Feb. 28, 1986; revised June 12, 1986; accepted June 12, 1986.

We are indebted to Dr. Simon LeVay for making the electrophysiological recordings and for his helpful comments on the manuscript. We also wish to thank Mr. Jim Rakos for technical assistance, Mr. Kris Trulock for photographic help, and Ms. Pat Thomas for typing the manuscript. This work was supported in part by Grant EY-03653 from the National Eye Institute. W.M.C. is a Senior Investigator and D.D.M.O. and J.W.F, are Investigators of the Clayton Foundation.

Correspondence should be addressed to Dr. Dennis D. M. O'Leary, Department of Neurosurgery, Box 8057, Washington University School of Medicine, St. Louis, MO 63110.

Copyright (C) 1986 Society for Neuroscience $0270-6474 / 86 / 123692-14 \$ 02.00 / 0$
}

axons for some form of trophic factor that is produced in limited amounts within the target region. It has been suggested that the initial overproduction of neurons serves to ensure that each target structure receives an adequate input and that the subsequent elimination of a proportion of the neurons serves to quantitatively match the size of the projecting neuronal populations to the functional needs of their targets-in other words, the phenomenon is a form of "systems matching" (for reviews, see Cowan and O'Leary, 1984; Cowan et al., 1984; Hamburger and Oppenheim, 1982; Oppenheim, 1981). However, it has become evident recently that another important consequence of such naturally occurring cell death is that it effectively eliminates certain developmental "errors," and, in particular, those in which axons project aberrantly (for reviews, see Clarke, 1981; Cowan et al., 1984; O'Leary, 1987).

Several "errors" of this kind have been reported in the past decade, especially in the avian and mammalian visual systems. For example, early in development a small number of the cells in the isthmo-optic nucleus (the source of the centrifugal innervation of the avian retina) send their axons to the "wrong" (i.e., the ipsilateral) eye (Clarke and Cowan, 1976; O'Leary and Cowan, 1982). Similarly, in both chicks (McLoon and Lund, 1982; O'Leary et al., 1983b) and rats (Bunt et al., 1983), some retinal axons have been found to cross into the contralateral optic nerve and to grow to the contralateral eye. Other retinal fibers in chicks grow to the ipsilateral, rather than to the contralateral, optic tectum (McLoon and Lund, 1982; O'Leary et al., 1983b; Thanos and Bonhoeffer, 1984), and in rodents the retina initially projects to all parts of the ipsilateral superior colliculus, whereas in adults its projection is confined to a small region along the rostral and medial margins of the colliculus (Frost and Schneider, 1979; Godement et al., 1984; Insausti et al., 1985; Land and Lund, 1979). Furthermore, some retinal axons have been found to extend beyond the lateral geniculate nucleus to the ventrobasal complex and the medial geniculate nucleus, and beyond the superior colliculus to the inferior colliculus and midbrain tegmentum; yet others are often misrouted to the substantia nigra or may even extend through the cerebral peduncle to the pons (Frost, 1984). These "aberrant" connections are found consistently at certain stages in development and in normal animals are either entirely or largely eliminated during the phase of naturally occurring retinal ganglion cell death. At present we cannot rule out the possibility that some of these short-lived connections play a transient role in the development of the visual system (see, for example, O'Leary and Thanos, 1985), but on the whole this seems unlikely, and we are probably justified in thinking of them as being due either to the misrouting of fibers into inappropriate pathways or to errors in target selection.

There is a third type of axonal targeting error during normal development which, to date, has received comparatively little attention. This includes those cases in which axons follow their 
normal pathways and grow to their correct targets but terminate in an inappropriate region within the target. Such "topographic targeting errors" are more difficult to discern with commonly available methods and usually can be detected only in those neural systems in which one population of neurons projects upon another in a precise, topographically ordered manner. One such a system is the retinal projection to the contralateral superior colliculus; for several reasons, this system is particularly favorable for experimental analysis in the rat brain. First, in adult rats, essentially all the retinal ganglion cells send axons to the superior colliculus (Linden and Perry, 1983), and, at least in mature animals, this projection is highly ordered. Thus ganglion cells in the nasal retina project to the caudal half of the contralateral colliculus, while those in the temporal retina project to the rostral part of the colliculus. Similarly, the upper retinal quadrants are represented laterally within the colliculus, while the inferior retina projects to the medial part of the colliculus (Siminoff et al., 1966). Second, much is known about the development of this system. For example, it has been established that, in rats, the retinal ganglion cells are generated between days 12 and 16 of gestation (Morest, 1970), and that their axons reach the contralateral superior colliculus as early as embryonic day (E) 16 (Bunt et al., 1983). The number of axons in the optic nerve reaches its peak on E20; thereafter there is a fairly rapid loss of ganglion cells, and by postnatal day (P) 10 the number of axons in the optic nerve is reduced by about two-thirds, with $90 \%$ of the loss occurring postnatally (Crespo et al., 1985). Third, during the first $10 \mathrm{~d}$ postnatally, the ipsilateral retinocollicular projection, which initially covers the entire extent of the colliculus, becomes progressively restricted to its rostromedial corner (Land and Lund, 1979). From dye-labeling experiments it is known that this restriction of the ipsilateral retinocollicular projection is due to the selective death of ganglion cells (Insausti et al., 1984; Jeffrey and Perry, 1982; O'Leary et al., 1983a).

In the present study we have taken advantage of some of these features of the rat retinocollicular projection to determine whether or not topographic targeting errors occur during normal development and to establish the fate of the ganglion cells whose axons project to inappropriate regions of the colliculus. For this, the fluorescent dyes are especially useful, since it is known that some of them - particularly fast blue (FB) (Bentivoglio et al., 1980) and true blue (Bentivoglio et al., 1979) - are taken up by axon terminals and transported back to the parent cell bodies, where they can remain for several weeks without fading or leakage and apparently without affecting the viability or subsequent development of the labeled neurons (Innocenti, 1981; O'Leary et al., 1981; Sawchenko and Swanson, 1981). They can, therefore, be used as long-term markers to follow the fates of cells and to clarify whether the disappearance of an axonal projection is due to cell death or to the withdrawal of axon collaterals (see, for example, Bunt et al., 1983; Crandall et al., 1985; Innocenti, 1981; Insausti et al., 1984; Ivy and Killackey, 1982; O'Leary and Cowan, 1982; O'Leary and Stanfield, 1986; O'Leary et al., 1981, 1983a; Price and Blakemore, 1985; Stanfield and O'Leary, 1985; Stanfield et al., 1982). By making small injections of FB, localized to the extreme caudal part of the superior colliculus on the day of birth or shortly thereafter, it is possible, in retinal whole-mount preparations, to identify ganglion cells that had sent their axons aberrantly to the labeled regions and, by comparing the findings in animals that were allowed to survive beyond the phase of naturally occurring cell death with those killed within $1-2 \mathrm{~d}$ of the dye injection, to determine the fate of the aberrantly projecting ganglion cells. Using this approach, we have been able to show that during normal development a significant number of retinal ganglion cells do indeed make errors of this kind and, furthermore, that more than $90 \%$ of the aberrantly projecting cells are eliminated by the middle of the second postnatal week.
These findings have led us to examine the role of ganglion cell activity in the elimination of these aberrantly projecting ganglion cells. Two recent observations suggested that this might be an important factor. The first was the finding that, following regeneration of the optic nerve in goldfish, the retinotectal map is initially somewhat disorganized but becomes progressively refined by an activity-dependent mechanism (Meyer, 1983; Schmidt and Edwards, 1983). The second was our finding that impulse activity in retinal axons plays a critical role in the preferential elimination of ipsilaterally projecting retinal ganglion cells that leads to the progressive restriction of the ipsilateral retinocollicular projection (Fawcett et al., 1984). A portion of this work has been presented in abstract form (O'Leary et al., 1984).

\section{Materials and Methods}

\section{Animals}

Over 200 newborn and young albino rats of the Sprague-Dawley strain were used for this study. Pregnant female animals were either obtained from a supplier or bred in our own animal facility. We refer to the first $24 \mathrm{hr}$ after birth as postnatal day $0(\mathrm{P} 0)$.

\section{Labeling procedures}

The experimental procedure in all cases involved making small injections of FB close to the caudal margin of the right superior colliculus. This site was chosen for 2 reasons: first, to avoid the coincidental labeling of fibers of passage that are known to take up and retrogradely transport FB (Sawchenko and Swanson, 1981)-since retinal fibers enter the superior colliculus from its rostral aspect, more rostral injections could well label ganglion cells whose axons pass through the injection site to terminate in more caudal regions of the colliculus; and second, becausc caudally placed injections should permit the identification of the most striking long-range topographic targeting errors.

The animals were injected with FB on P0, P10, or P12. For this, the rats were anesthetized with open ether, and a small opening was made in the skull overlying the caudal part of the right superior colliculus. A glass micropipette (tip diameter, $25 \mu \mathrm{m}$ ), attached to a $1 \mu$ l Hamilton syringe, was then lowered through the opening to just beneath the surface of the colliculus, and 0.01 or $0.025 \mu \mathrm{l}$ (depending on the age of the animal) of a $2 \%$ suspension of FB was injected. The skin wound was sutured and the animal was returned to its mother. Following the appropriate postinjection survival period, the rats were reanesthetized with chloral hydrate and perfused transcardially with $0.9 \%$ saline, followed by $10 \%$ neutral buffered formalin. The rats, which were injected on P10 or P12, were allowed to survive for about $48 \mathrm{hr}$; about half of those injected on P0 were perfused $30 \mathrm{hr}$ later, and the remainder were killed on P12. The perfused brains were removed and, together with the eyes, were stored overnight at $4^{\circ} \mathrm{C}$ in the fixative, to which $10 \%$ sucrose had been added. After removing the cerebral hemispheres, the remaining part of the brain was frozen and sectioned sagittally at $50 \mu \mathrm{m}$ on a sliding microtome. A 1-in-2 series of sections throughout the extent of the

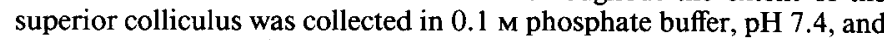
mounted onto gelatin-coated slides. Retinal whole-mounts were prepared and placed onto clean glass slides in a buffered glycerol mountant and then coverslipped. Four incisions were made into the retinal periphery of each eye; 1 incision was always made at the ventral midline, and this cut was extended to the optic disc so as to provide a frame of reference for subsequent orientation of the whole-mount.

\section{TTX treatment}

In a separate series of rats, the sodium channel-blocking agent tetrodotoxin (TTX) was injected into one or the other eye to determine whether the fate of the incorrectly projecting ganglion cells had been influenced by impulse activity in retinal axons. As before, FB was injected into the caudal part of the right superior colliculus on P0, P10, or P12. The TTX treatment was begun on the day of birth and repeated on alternate days or, in some cases, every day. For this, the eyelid of either the left or right eye was opened, and the exposed eye was washed with $2 \%$ chloramphenicol in $70 \%$ ethanol. The eye was then punctured near the ciliary margin with a fine tungsten needle, and a glass micropipette filled with TTX (Sigma; $1 \mathrm{mg} / \mathrm{ml}, 3.1 \times 10^{-3} \mathrm{M}$ ) was inserted 

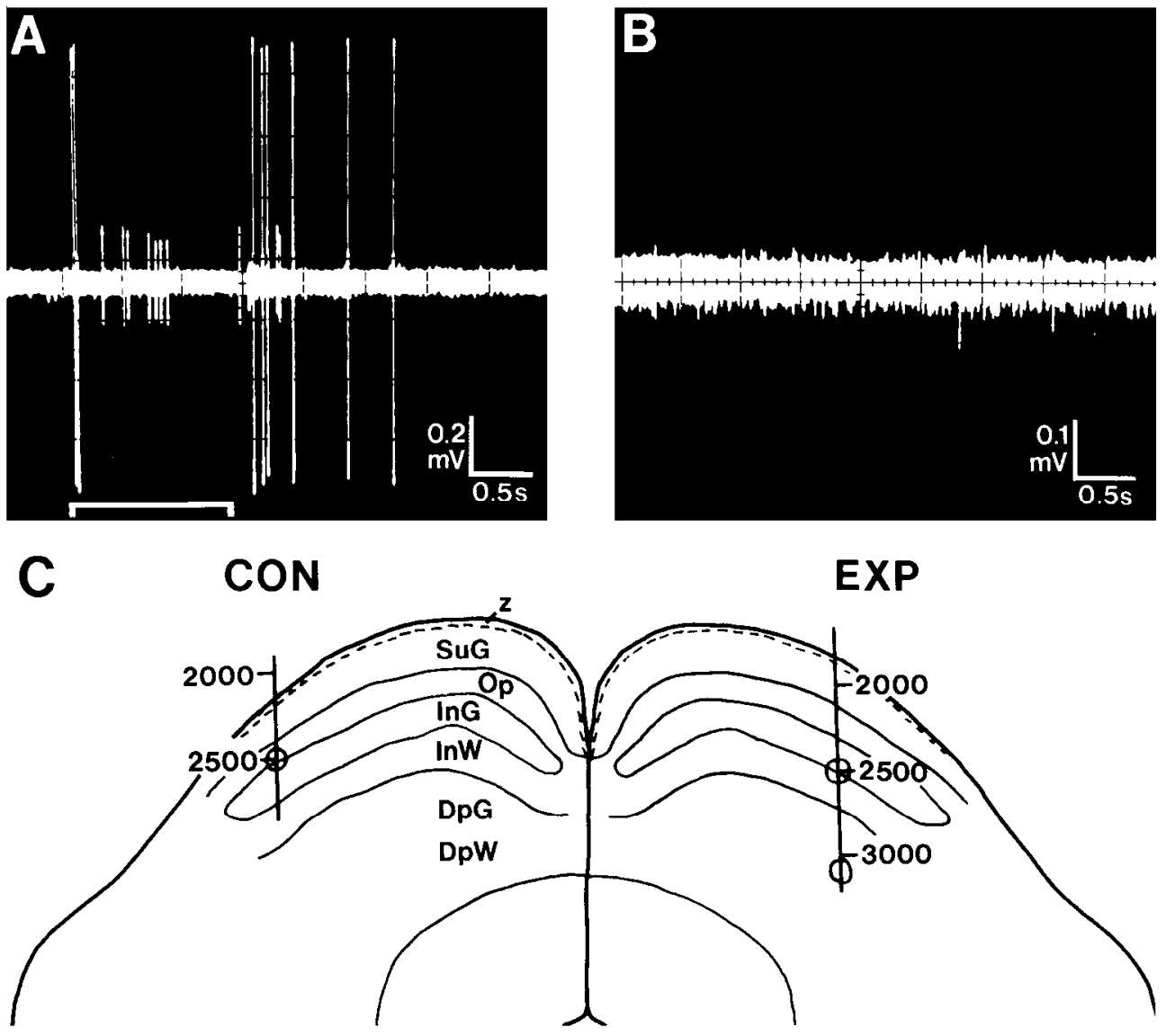

Figure 1. Representative traces $(A$ and $B$ ) recorded from the superior colliculi of a P19 rat $47 \mathrm{hr}$ after it was injected with TTX. $C$ shows the electrode penetrations (vertical lines) and marking lesions (open circles) on a drawing of a coronal section through the colliculi. The depths given are in microns below the surface of the brain. $A$, Two isolated units recorded at a depth of $2480 \mu \mathrm{m}$ within the optic layer $(O p)$ of the control, left colliculus $(C O N)$, displaying both $\mathrm{ON}$ and $\mathrm{OFF}$ responses to a diffuse light shined into the normal, uninjected right eye. The estimated duration of the light stimulus is indicated by the horizontal white line below the trace. $B$, Multiunit spontaneous activity recorded within the deep gray layer $(D p G)$ of the experimental, right colliculus $(E X P)$ at a depth of $3100 \mu \mathrm{m}$. Throughout the entire penetration, no responses could be evoked from the left, TTX-injected eye. The colliculus was virtually silent until the electrode entered the deeper layers (see text for further details). Abbreviations for collicular layers: $D p W$, deep white; $\operatorname{In} G$, intermediate gray; $\operatorname{In} W$, intermediate white; $S u G$, superficial gray; $z$, zonal.

through the puncture hole until its tip lay deep within the posterior chamber. Between 0.04 and $0.08 \mu$ l (again depending on the age of the animal) of the TTX solution was injected, using an air-pressure system. The eye was washed again with the chloramphenicol solution and the animal was returned to its mother. In a control series of animals, the left eye was injected in the same way but with a citrate buffer of the same molarity $(0.1 \mathrm{M})$ and $\mathrm{pH}(4.8)$ as the vehicle in which the TTX was dissolved. These animals were injected with $\mathrm{FB}$ on $\mathrm{P} 0$.

\section{Effectiveness of the TTX injections}

The amount of TTX injected was between one-quarter and one-half the dose we had found, in preliminary experiments, to be lethal after a single intraocular injection at the relevant ages. At these doses, roughly a quarter of the pups died over the course of the 6 or 7 injections administered on alternate days between P0 and P12 or P14. There can be no doubt that at these doses all ganglion cell activity was blocked, but to be sure the activity block persisted for at least $2 \mathrm{~d}$, we carefully monitored the pupillary light reflex in the TTX-treated animals, and in a separate group of rats the effectiveness of the TTX injections was examined electrophysiologically.

As Dubin et al. (1986) have reported, in TTX-injected eyes there is a good correlation between the abolition of the pupillary light reflex and the duration of the blockade of ganglion cell activity. To monitor the pupillary light reflex, the rat pups were anesthetized with open ether, the eyelids were opened, the head was positioned under a dissecting microscope in a dimly lit room, and a bright light was directed into the TTX-treated and untreated eyes, in turn. We found it difficult to elicit a pupillary light reflex in either control or TTX-treated rats during the first postnatal week. However, after P8 it was easy to demonstrate that the reflex was blocked in the TTX-injected eyes $2 \mathrm{~d}$ after the last TTX injection. That the TTX treatment did not result in a generalized neuronal activity block was evidenced by the fact that the pupillary light reflex elicited from the uninjected eyes appeared to remain normal. These findings agree well with those of Riccio and Matthews (1985), who found it took $2 \mathrm{~d}$ for the pupillary light reflex to recover from TTX blockade in P14-21 rats following TTX injections equivalent to onefifth the dose used in our experiments. If TTX leaves the eyes of young rats at about the same rate as in kittens (in which the half-time is on the order of $7 \mathrm{hr}$; Dubin et al., 1986), it seems likely that the blockade of both the pupillary light reflex and ganglion cell activity should persist for at least $2.5 \mathrm{~d}$.

To establish more directly that ganglion cell activity is blocked for at least $2 \mathrm{~d}$ following an intraocular TTX injection, physiological recordings were made from the superior colliculi. We could not consistently obtain good visually evoked responses in the superior colliculi of normal P14 rats, probably because of the immaturity of the intraretinal connectivity at this age (see Weidman and Kuwabara, 1968). We therefore used slightly older animals, injecting, as described above, the left eyes of a group of 7 pups with $0.08 \mu \mathrm{l}$ of the standard $0.1 \%$ solution of TTX (the same dose we gave to P8 and older pups) on P13, P15, and P17. Recordings were made on P19, about $48 \mathrm{hr}$ after the last injection of TTX. The rats were anesthetized with chloral hydrate $(3.5 \mathrm{mg} / 10 \mathrm{gm})$ and placed in a Kopf stereotaxic frame. The skull and dura overlying the superior colliculus on both the control and experimental sides were 

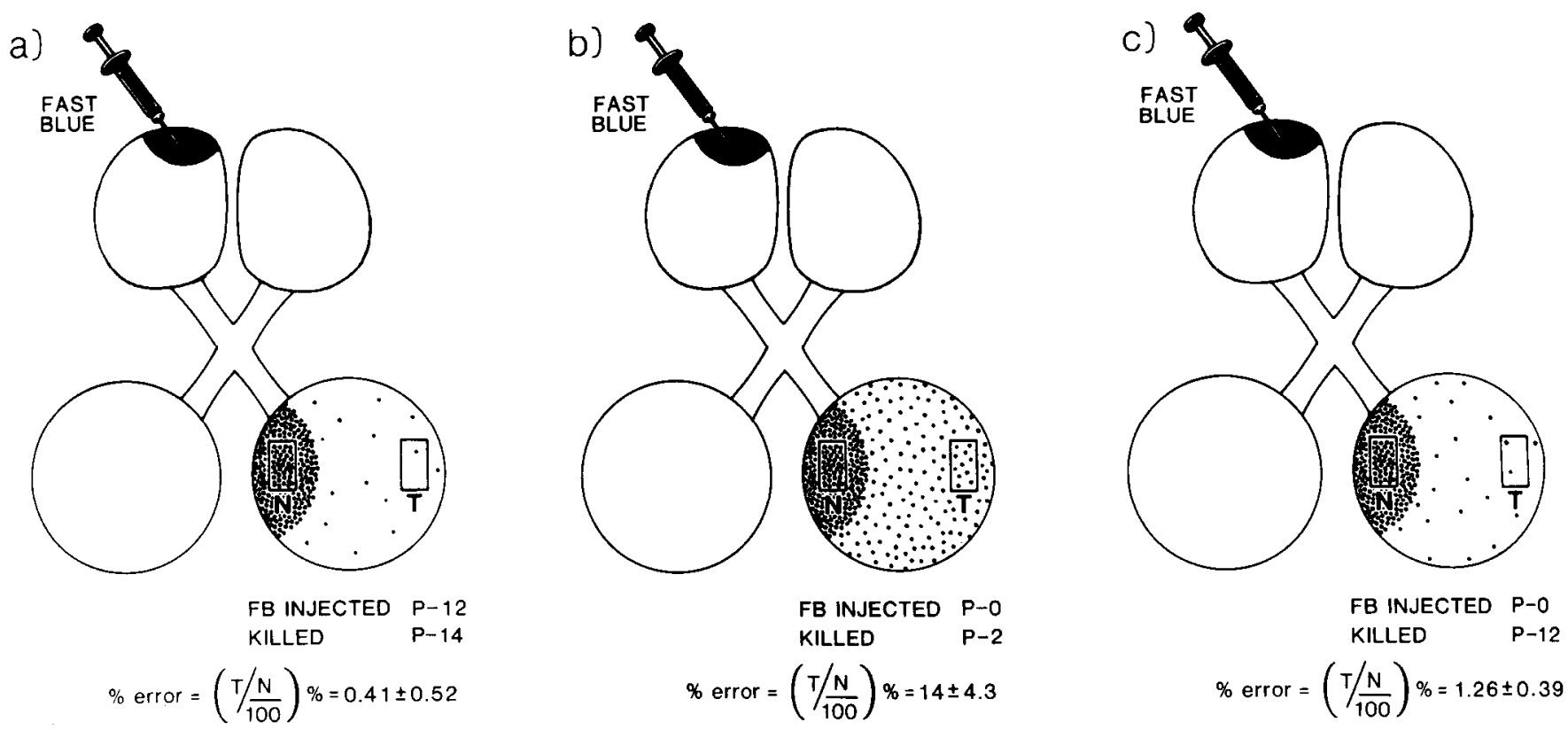

Figure 2. A schematic diagram illustrating the 3 main experimental paradigms we have used to show that long-range topographic targeting errors occur in the crossed retinocollicular projection in normal rats, and also that ganglion cell death is responsible for their elimination. In each experimental group, a localized injection of FB was made into the extreme caudal part of the right superior colliculus, and, some time later, wholemount preparations of the left retina were made. The densities of the labeled ganglion cells in the region of maximum labeling density in the peripheral nasal retina $(N)$ and in the mirror-image region of the temporal retina $(T)$ were then estimated. From these density estimates, a percentage error figure was calculated. The mean percentage error $( \pm \mathrm{SD})$ for each group of experiments is indicated beneath each drawing.

carefully removed and a vinyl-insulated tungsten microelectrode $\mathrm{CH}-$ bel, 1957) was lowered orthogonal to the surface of the brain with a Kopf microdrive. Lesions were made at points along the penetrations by passing a small current ( $2 \mu \mathrm{A}$ for $5 \mathrm{sec}$, electrode positive) through the recording electrode. On the left side, single- or multiunit responses to diffuse-light stimulation of the right (uninjected) eye were obtained over about a $300-\mu \mathrm{m}$-long portion of the penetration, beginning just below the surface of the colliculus. Most of the isolated units (Fig. 1A) and all of the unresolved multiunit activity gave both $\mathrm{ON}$ and $\mathrm{OFF}$ responses. It could not be determined whether these recordings were from optic nerve fibers or collicular neurons. In the right colliculus, no responses could be clicitcd by stimulation of the left (TTX-injected) eye, although multiunit spontaneous activity was encountered within the deep layers of the colliculus (Fig. 1B). Responses to other modalities were not tested.

\section{Optic nerve sections}

The optic nerves of each animal injected with TTX were removed after perfusion and postfixed overnight at $4{ }^{\circ} \mathrm{C}$ in a solution of $2 \%$ glutaraldehyde and $2 \%$ paraformaldehyde in $0.1 \mathrm{~m}$ phosphate buffer. The nerves were then rinsed in cacodylate buffer, osmicated, dehydrated in a graded series of alcohols, and embedded in Spurr's resin. Semithin $1 \mu \mathrm{m} \mathrm{sec-}$ tions were cut at about the midpoint of each nerve; these sections were mounted onto glass slides and stained with toluidine blue for light microscopy. A section from each nerve was photographed in a Leitz Orthomat microscope, and the prints were enlarged to give a total magnification of $300 \times$. The total cross-sectional area of each nerve, excluding the areas occupied by cell bodies, large glial processes, and blood vessels, was determined on a digital data tablet. In some representative cases, ultrathin sections were cut from both nerves, mounted on grids, and examined and photographed in a Zeiss 109 electron microscope. Estimates of the cross-sectional area of neuropil were made from photomontages ( $2000 \times$ final magnification), and estimates of the mean axon density in the nerves were made from high-power micrographs $(38,400 \times$ final magnification). In some cases, the total numbers of axons on the TTX-treated and control sides were calculated from these figures (see O'Leary et al., 1986, for details).

\section{Analysis}

Injection sites. Prior to sectioning, the cerebral hemispheres were removed and, using a Wild dissecting microscope with an attached drawing tube, we made a tracing of the dorsal surface of the midbrain, with the location of the injection site in the superior colliculus marked. The brains were then sectioned, as described above, and the spread of the injected FB in the colliculus was determined by examining the relevant sections with a Leitz Dialux 20 epifluorescence microscope equipped with a $100 \mathrm{~W}$ mercury light source and an " $\mathrm{A}$ " filter cube. In selected cases, the full extent of the injection site was then reconstructed on the drawing of the dorsal surface of the colliculus.

Counts of retinal ganglion cells. Only those cases in which the injections were restricted to the caudal margin of the colliculus and were about the same relative size were used for the quantitative analyses. Whole-mounts of the retina contralateral to the FB-injected superior colliculus were examined with the epifluorescence microscope. Counts of the FB-labeled ganglion cells were made at $200 \times$ with the aid of an eyepiece reticle that measured $0.45 \times 0.45 \mathrm{~mm}$ and was subdivided into a $5 \times$ 5 -grid network. All the FB-labeled ganglion cells within an area equivalent to 1-4 grid squares were counted in the region with the highest density of labeled ganglion cells. As a rule, the labeled cells in a much larger arca (cquivalent to that covered by up to 10 grid squares) were counted in the mirror-image position on the opposite side of the same retina. This larger area was counted in order to allow for fluctuations in the density of labeled cells in a region in which they were usually not very numerous. The number of FB-labeled ganglion cells per unit area in the lowdensity region was then computed as a percentage of the number of FB-labeled ganglion cells in an area of equal size in the region containing the highest density of labeled cells. For convenience, we have termed this figure the "percentage error" (see below).

\section{Results}

\section{Normal animals}

The topographic distribution of retinal ganglion cells labeled by fast blue injections after the period of naturally occurring cell death. Counts of the number of axons in the optic nerve have 

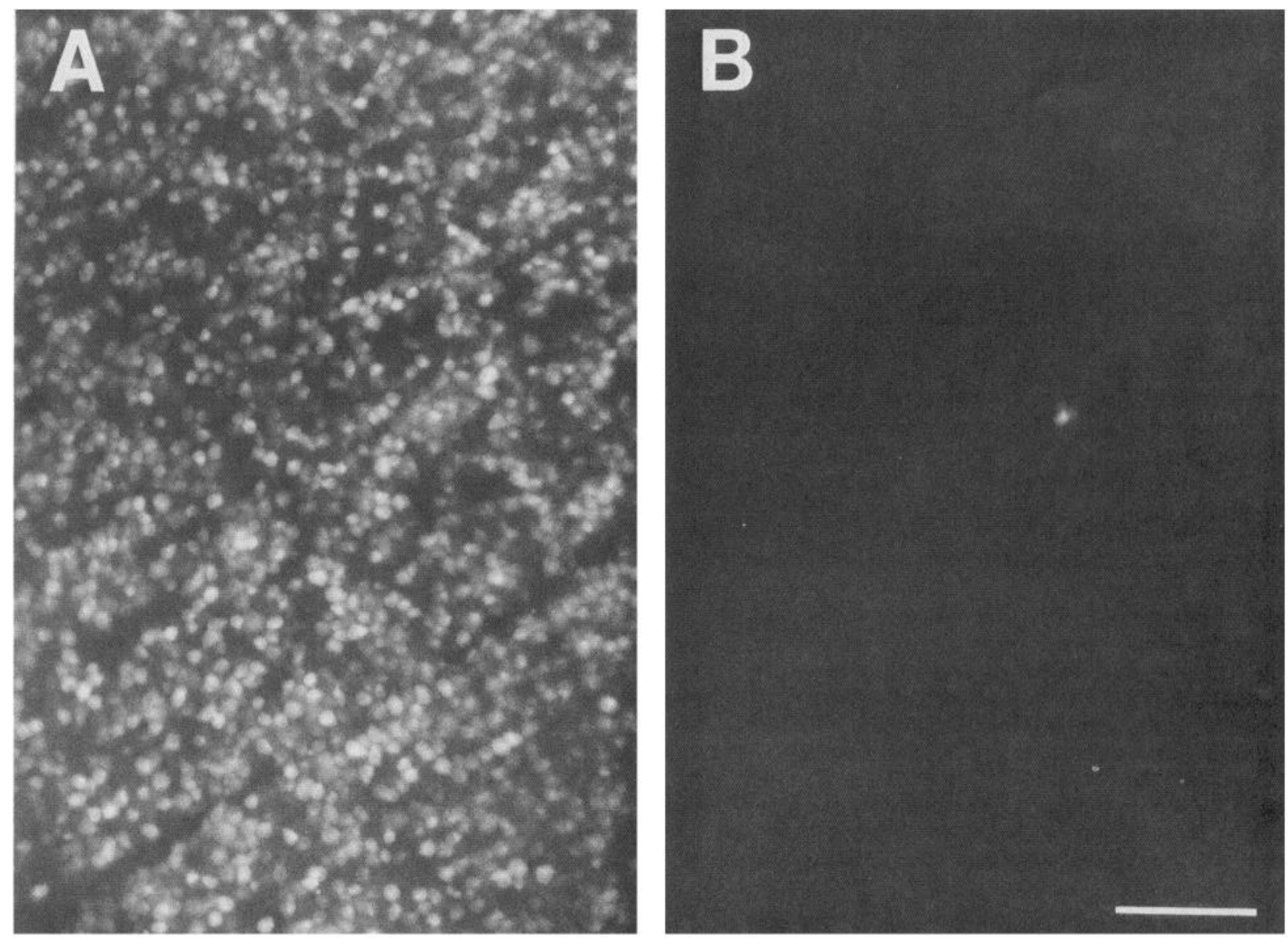

Figure 3. Fluorescence photomicrographs of a whole-mount of the left retina from a rat injected with FB on P12 and killed on P14, showing the density of the retrogradely labeled ganglion cells in the region of highest labeling density in the peripheral nasal retina $(A)$ and in the mirror-image region at the periphery of the temporal retina $(B)$. Scale bar, $250 \mu \mathrm{m}$.

established that the phase of "naturally occurring" ganglion cell death in the rat retina begins shortly before birth and is complete by about P10, with about $90 \%$ of the loss occurring postnatally (Crespo et al., 1985). In order to estimate the degree of variability in the projection of the retina upon the superior colliculus following the completion of the phase of ganglion cell death, we made a small $(0.025 \mu \mathrm{l})$ injection of FB into the caudal part of the right superior colliculus in 22 rats on P12 and allowed the animals to survive until P14 (Fig. $2 a$ ). In 8 of these cases, the injection was confined, as intended, to the caudal fifth of the superior colliculus. In the other cases, the injection had either involved principally the inferior colliculus or was placed further rostrally than we had planned: these cases were excluded from the quantitative analyses; however, those in which the more rostral parts of the superior colliculus had been injected were useful in that they served to confirm the general topographic organization of the retinocollicular projection. Thus, the most rostral injections (which involved the midportion of the colliculus) resulted in the labeling of a dense patch of ganglion cells near the center of the contralateral retina. After more caudal injections, the labeled ganglion cells were found further nasally within the retina. When the injections involved mainly the medial part of the colliculus, the zone with the highest density of labeled ganglion cells was in the inferior retina. Conversely, the highest density of labeled cells was found in the upper half of the retina when the injection site involved the lateral part of the colliculus. But especially important for our purposes was the finding that, in each of these cases, there was only a small number of labeled ganglion cells outside the zones of high-density labeling.

In each of the 8 cases in which the FB injection was confined to the caudal part of the superior colliculus, there was a welldefined region containing a high density of labeled ganglion cells along the periphery of the nasal part of the contralateral retina (see Fig. 3A). In every case, however, there was also a small number of labeled ganglion cells scattered across the rest of the retina. The relative paucity of such cells is shown in the photomicrograph in Figure $3 B$, which is taken from the mirrorimage region corresponding to that shown in Figure $3 A$ (i.e., from the periphery of the temporal retina). From what we know of the retinotopic order of the retinocollicular projection, we can identify the labeled ganglion cells in the region of high density at the nasal periphery as cells that have made the "correct" topographic projection, and we can consider the scattered ganglion cells that lie well outside this zone (like those in Fig. $3 B$ ) as cells whose axons have made a "topographic targeting error."

To estimate the relative numbers of correctly and incorrectly projecting ganglion cells, we first determined the density of labeled ganglion cells in the most heavily labeled region in the peripheral nasal retina. Typically, this ranged from about 2800 to $4900 / \mathrm{mm}^{2}$. The density of FB-labeled cells in the corresponding region at the temporal periphery varied from about 0 to 28 / $\mathrm{mm}^{2}$. It is convenient to express these figures as the number of incorrectly projecting ganglion cells per 100 correctly projecting cells for equal areas of retina and to refer to this as the percentage 

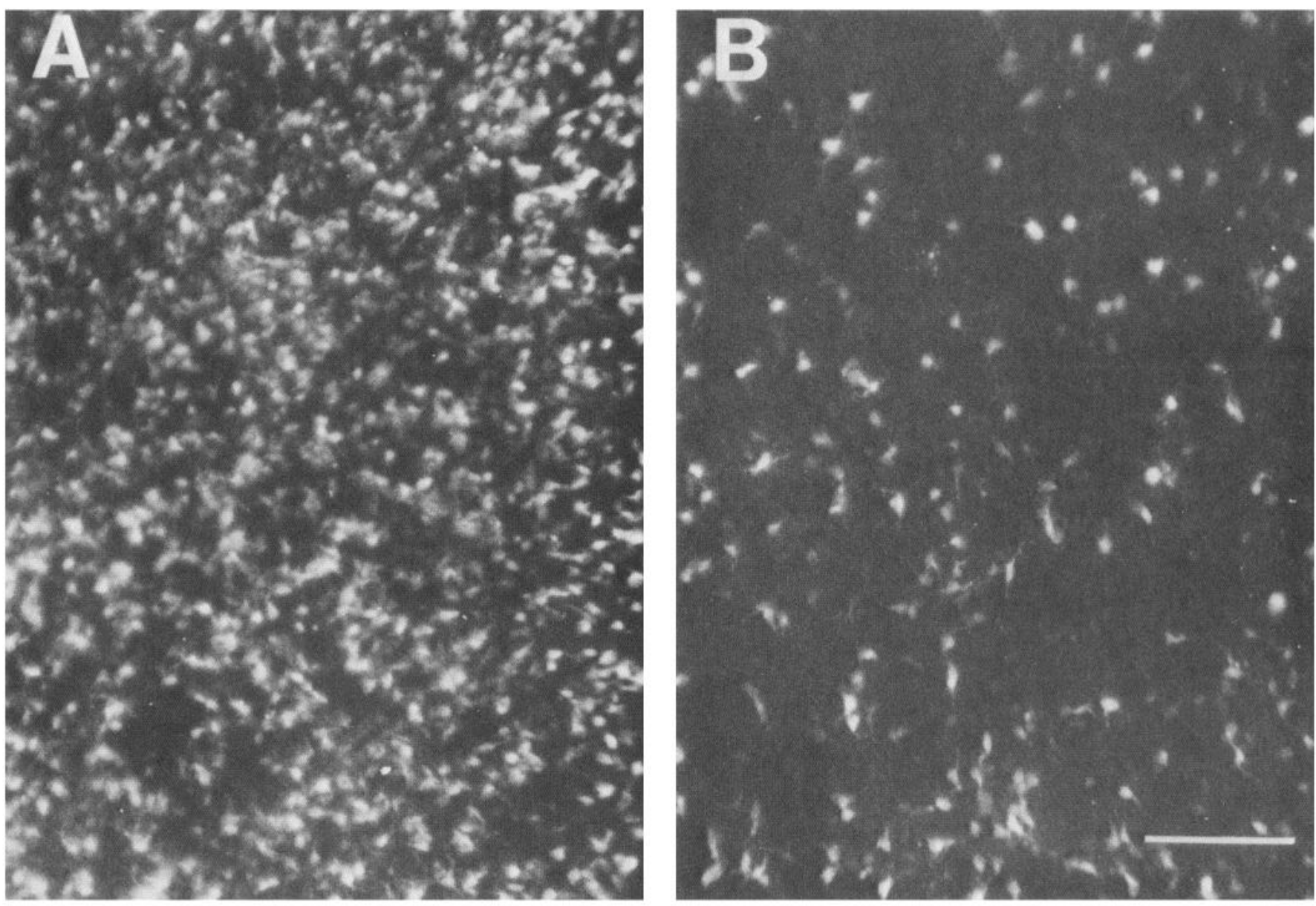

Figure 4. Fluorescence photomicrographs of a whole-mount preparation of the left retina from a rat in which FB was injected into the caudal part of the right colliculus early on P0, showing the density of labeled ganglion cells on P1. $A$ is from the region of highest labeling density in the nasal retina, while $B$ is from the corresponding region at the periphery of the temporal retina. Scale bar, $250 \mu \mathrm{m}$.

error. The percentage error calculated in this way for the 8 cases in which the injection was confined to the caudal colliculus is given in Table 1. It ranged from 0.00 to 1.56 , with a mean of $0.41 \pm 0.52$ (SD). In other words, by P14 there was, on average, less than 1 labeled ganglion cell in the peripheral part of the temporal retina for every 100 labeled ganglion cells in the most heavily labeled region of the nasal retina.

The topographic distribution of labeled ganglion cells following fast blue injections into the caudal colliculus in newborn rats. To determine the distribution of the retinal ganglion cells that project to the caudal part of the colliculus shortly after the formation of the retinocollicular projection, we attempted to make a small injection $(0.01 \mu \mathrm{l})$ of FB into the caudal part of the right superior colliculus in a series of rats on the day of birth, killing them late on P1 or early on P2 (see Fig. $2 B$ ). In 13 of the 47 animals injected in this way, the injection was found, on histological examination, to be confined to the caudal edge of the colliculus. Although the size of the injections varied somewhat in these cases, in the majority it was centered near the middle of the mediolateral extent of the caudal margin of the superior colliculus. The injection site in a typical case is shown in Figure 5.

In contrast to our findings in the rats that were injected after the period of naturally occurring ganglion cell death, in the whole-mount preparations of the retinas from these neonates, we found large numbers of labeled ganglion cells scattered across the entire retina, although, again, the highest density of labeled cells was within the peripheral nasal retina. Photomicrographs of the labeled ganglion cells near the nasal periphery and in the corresponding region of the temporal retina from the case illustrated in Figure 5 are shown in Figure 4, $A$ and $B$, respectively. Using the same procedure described in the preceding section, we determined the percentage error for the 13 cases injected on $\mathrm{P} 0$ and killed on $\mathrm{P} 1$ or $\mathrm{P} 2$; the calculated figures ranged from a low of 9.3 to a high of 22.7 , with an average of $14 \pm 4.3$ (Table 1). That is, for every 100 labeled ganglion cells in the region with the highest density of labeled cells at the nasal periphery (in which the densities ranged from about 7000 to $10,500 / \mathrm{mm}^{2}$ ), there were, on average, about 14 labeled ganglion cells in the mirror-symmetric region in the peripheral temporal retina. This is about 35 times the mean figure found in our control animals injected on P12 and killed on P14. The consistency of this finding indicates that during the development of the retinocollicular projection a significant proportion of the retinal ganglion cells send their axons (or possibly axon collaterals; see below) to topographically inappropriate regions of the superior colliculus.

The design of our experiments was such as to specifically identify targeting errors within the rostrocaudal dimension of the colliculus, but careful examination of the 13 cases that met our criteria for a successful FB injection made it evident that errors also occur within the mediolateral dimension of the projection. The evidence for this is derived from a qualitative assessment of the relative densities of the labeled ganglion cells 


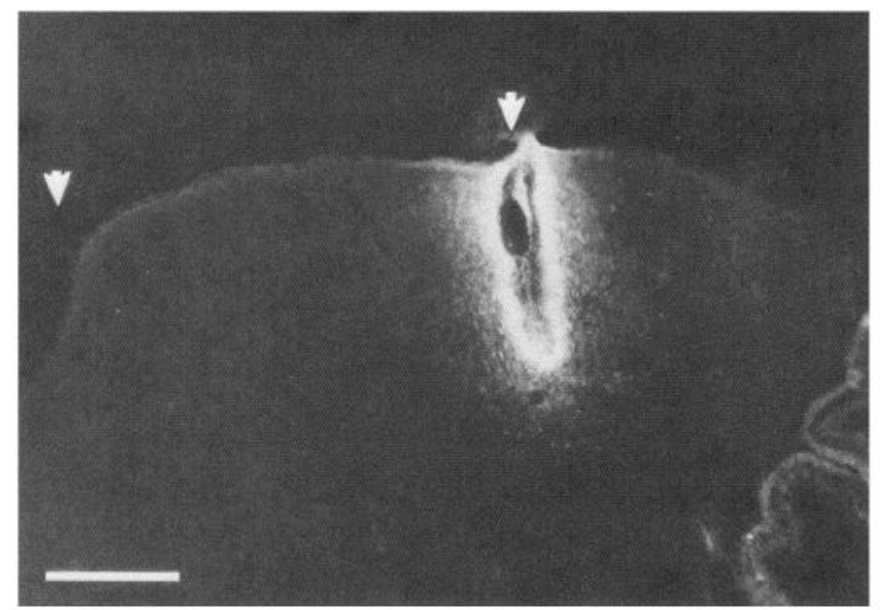

Figure 5. A fluorescence photomicrograph of a sagittal section through the midbrain and adjoining regions showing the limited spread of the FB injection into the caudal margin of the superior colliculus in a rat injected early on the day of birth (P0). The arrow to the left indicates the rostral margin of the superior colliculus, while the arrow on the right marks the border between the superior and inferior colliculi. Scale bar, $500 \mu \mathrm{m}$.

in different regions of the retina. In every case, the highest density of labeled cells in the nasal retina was found in the appropriate retinotopic sector. Within the temporal retina, the highest density of labeled cells was always found in the region that, in a mature animal, would project to the area of colliculus rostral to the primary focus of the injection. However, significant numbers of labeled ganglion cells were also found in areas well off the direct rostrocaudal line of projection. The axons of the labeled ganglion cells in these areas must have been misdirected along the mediolateral dimension of the colliculus, in addition to extending well beyond their appropriate termination zone near the rostral pole of the colliculus.

The fate of the incorrectly projecting retinal ganglion cells. It is clear from the findings presented in the preceding sections that between the time of birth and the end of the second postnatal week the retinocollicular projection undergoes a substantial reorganization. The net result of this change is an obvious refinement in the precision of the projection, which is due to the removal of most of the topographically inappropriate con- nections. A priori, this could be brought about in 3 ways. First, the incorrectly projecting axons could relocate their terminal arbors to a more appropriate region of the colliculus. Second, if all or most of the aberrant projections were due to collateral branches of axons that actually terminate within the correct retinotopic locus, or to the axon's having a very large terminal arbor, the selective elimination of the relevant collaterals would by itself sharpen the topographic order in the retinocollicular map. And third, the inappropriately projecting ganglion cells themselves could be eliminated during the phase of naturally occurring ganglion cell death. To determine which of these possibilities is correct, we have used FB as a long-term marker on the reasonable assumption that if the inappropriately projecting cells were to relocate their terminal arbors or simply to lose a misdirected axon collateral, they should still be detectable after the refinement of the projection when labeled by an injection of FB into the colliculus shortly after birth. On the other hand, if the inappropriately projecting ganglion cells died, they should no longer be recognizable when the refinement of the projection is complete.

To test this, we made a localized injection of $\mathrm{FB}$ into the caudal part of the colliculus on $\mathrm{P} 0$ in a group of 73 pups from several litters, and the animals were allowed to survive until P12, when their retinas were prepared for fluorescence microscopy (some of the pups from these litters were perfused on P1 or P2 and used for the short-term labeling experiments described above). In 13 of the 73 long-term labeling cases, the injection site was found to be confined to the caudal part of the superior colliculus, and in the contralateral retinas in each of these cases there were many fewer labeled ganglion cells in the temporal retina than in their littermates, which were injected in the same way and at the same time but killed on P1 or P2. Figure 6 shows 2 photomicrographs from the contralateral retina in a typical longterm labeling experiment to show the density of labeled cells in the nasal retina and in a comparable region within the temporal retina. Estimates of the percentage error in these 13 cases ranged from 0.66 to 1.85 , with a mean of $1.26 \pm 0.39$ (see Table 1). These figures are sufficiently similar to those from the 8 cases injected on P12 and killed on P14 to suggest that most of the ganglion cells whose axons had grown to inappropriate regions of the colliculus had, in fact, died during the phase of naturally occurring ganglion cell death, and that selective ganglion cell death is therefore the predominant mechanism by which such erroneously projecting axons are removed.

Tabie 1. Number of incorrectly projecting retinal ganglion cells/100 correctly projecting retinal ganglion cells in 3 groups of normal rats

Inject fast blue P12, kill P14

\begin{tabular}{ll}
\hline Case & Number \\
\hline PSC-116 & 0.00 \\
PSC-126 & 0.09 \\
PSC-114 & 0.12 \\
PSC-122 & 0.17 \\
PSC-121 & 0.26 \\
PSC-119 & 0.36 \\
PSC-10 & 0.72 \\
PSC-9 & 1.56
\end{tabular}

Mean $\pm \mathrm{SD}=0.41 \pm 0.52$
Inject fast blue $\mathrm{P} 0$, kill $\mathrm{P} 1 / \mathrm{P} 2$

\begin{tabular}{lc}
\hline Case & Number \\
PSC-129 & 9.3 \\
PSC-20 & 9.5 \\
PSC-78 & 10.1 \\
PSC-53 & 10.5 \\
PSC-128 & 11.4 \\
PSC-66 & 12.2 \\
PSC-80 & 12.8 \\
PSC-62 & 13.9 \\
PSC-127 & 14.5 \\
PSC-74 & 16.4 \\
PSC-21 18.2 \\
PSC-130 & 18.1 \\
PSC-17 & 20.1
\end{tabular}

Mean $\pm \mathrm{SD}=14 \pm 4.3$
Inject fast blue P0, kill P12

\begin{tabular}{ll}
\hline Case & Number \\
\hline PSC-113 & 0.66 \\
PSC-93 & 0.92 \\
PSC-111 & 0.95 \\
PSC-103 & 1.03 \\
PSC-46 & 1.16 \\
PSC-36 & 1.27 \\
PSC-35 & 1.43 \\
PSC-49 & 1.49 \\
PSC-59 & 1.79 \\
PSC-37 & 1.85
\end{tabular}

Mean $\pm \mathrm{SD}=1.26 \pm 0.39$ 

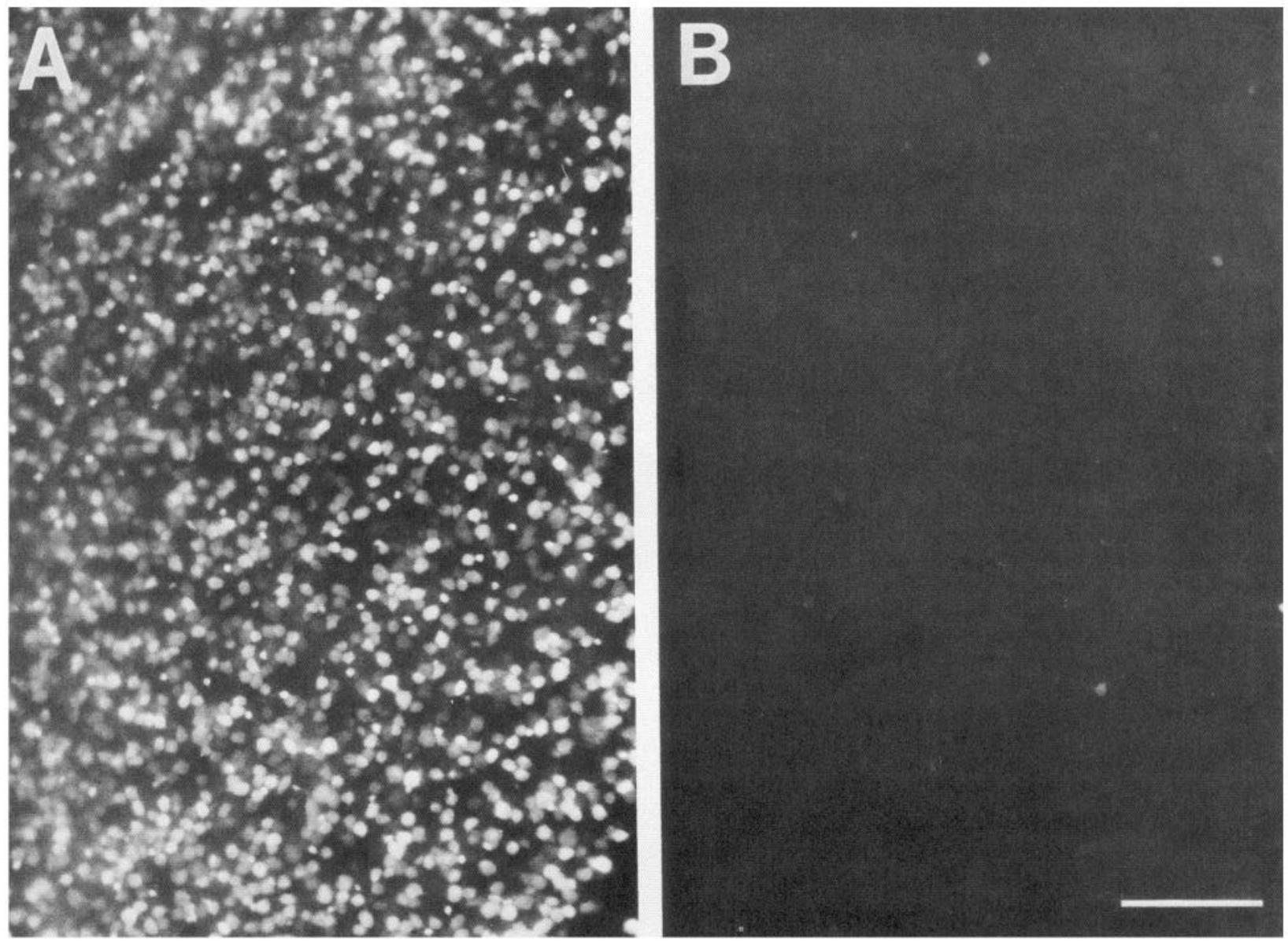

Figure 6. Fluorescence photomicrographs from a whole-mount preparation of the left retina of a P12 rat injected with FB early on P0, showing the density of labeled ganglion cells in the region of highest density in the nasal retina $(A)$ and in the corresponding region at the periphery of the temporal retina $(B)$. Scale bar, $250 \mu \mathrm{m}$.

\section{Experimental animals}

The effect of blocking ganglion cell activity on the elimination of topographic targeting errors. To determine whether impulse activity in the ganglion cells plays a role in the selective elimination of the early topographic targeting errors, we carried out 2 series of experiments involving the intraocular administration of TTX. In the first series of experiments, a small $(0.01 \mu \mathrm{l})$ injection of FB was made into the caudal part of the right superior colliculus in rat pups within a few hours of their birth. Beginning on the same day, and continuing on alternate days from P0 to P12, $0.04-0.08 \mu 1$ of a $0.1 \%$ solution of TTX was injected into the posterior chamber of the left eye (Fig. 7a). The animals were perfused on P12, and the brains and retinas prepared as before. To exclude cases in which the repeated TTX injections had damaged the retina, semithin sections of both optic nerves were prepared, and their cross-sectional areas were determined. Since areal measurements of this kind provide a good estimate of the relative numbers of axons in the nerve (O'Leary et al., 1986), we excluded those cases in which the cross-sectional area of the nerve from the TTX-treated eye was substantially smaller than that of the control nerve from the untreated eye.

Of the 14 animals that survived the full sequence of TTX injections, 6 had FB injections that were confined to the caudal part of the superior colliculus, and optic nerves that were similar in cross-sectional area on both sides. Although the size and location of the injection sites in these animals were comparable to those in the normal, long-term labeling cases described above, the distributions of the labeled ganglion cells were strikingly different. Indeed, they most closely resembled the normal shortterm labeling cases injected with FB on P0 and killed on P1 or P2. This is illustrated for a representative long-term labeling experiment in the photomicrographs of the zone of highest density of labeled ganglion cells in the nasal periphery and of the mirror-image region in the peripheral temporal retina shown in Figure 8 . These qualitative observations are borne out by estimates of the relative densities of labeled ganglion cells in the 2 regions (Table 2). There were 11.4-17.2 labeled cells in the temporal retina for every 100 labeled cells in the nasal periphery, giving a mean percentage error of $13.8 \pm 2.2$. This is very close to the figure of $14 \pm 4.3$ found in the normal animals injected on P0 and killed on P1 or P2. Since intraocular injections of TTX do not appear to substantially affect the overall number of cells that die during the period of naturally occurring ganglion cell death (O'Leary et al., 1986), the findings in these experiments strongly suggest that, when impulse activity in the ganglion cells is blocked by TTX, there is no tendency for the cells that make targeting errors to be selectively eliminated: The death of ganglion cells that occurs under these conditions is apparently random and is not preferentially directed against cells whose axons have grown to inappropriate regions of the colliculus.

While these experiments show that the ganglion cells that make targeting errors persist if activity in the entire ganglion cell population is blocked, they throw no light on the distribution of the axons of these cells within the colliculus. To address this 

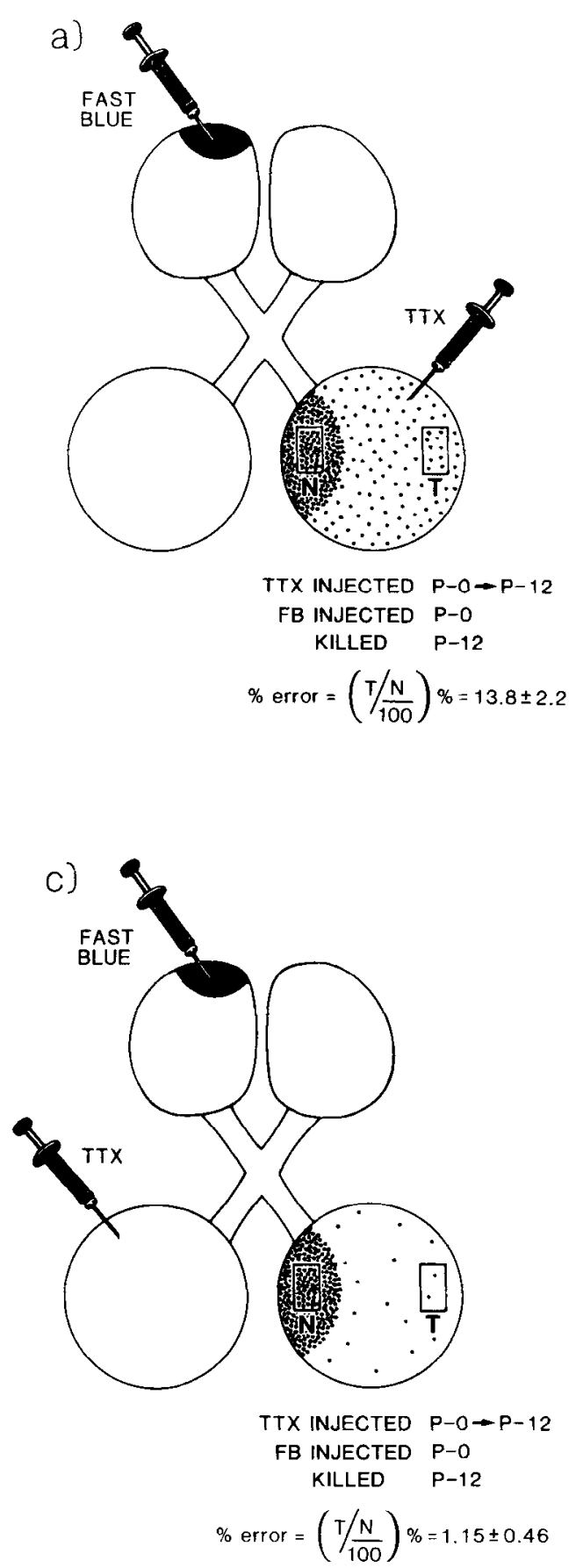

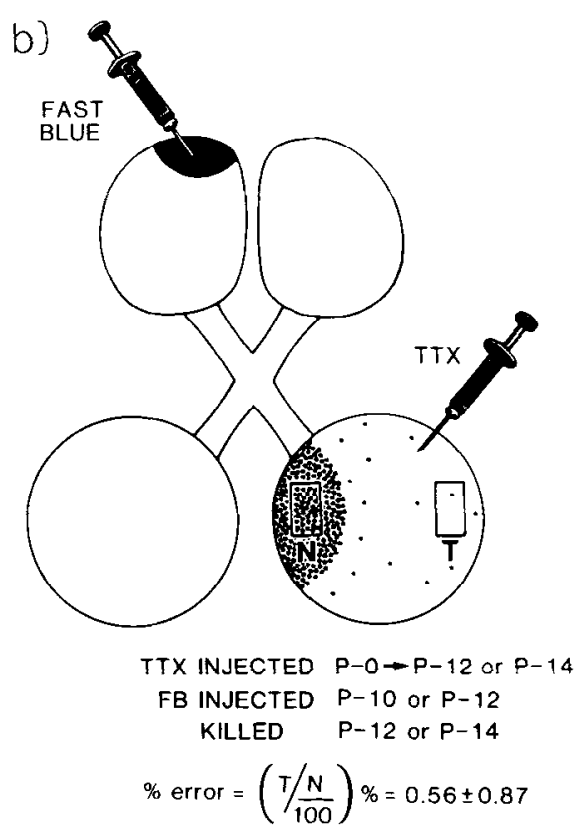

d)

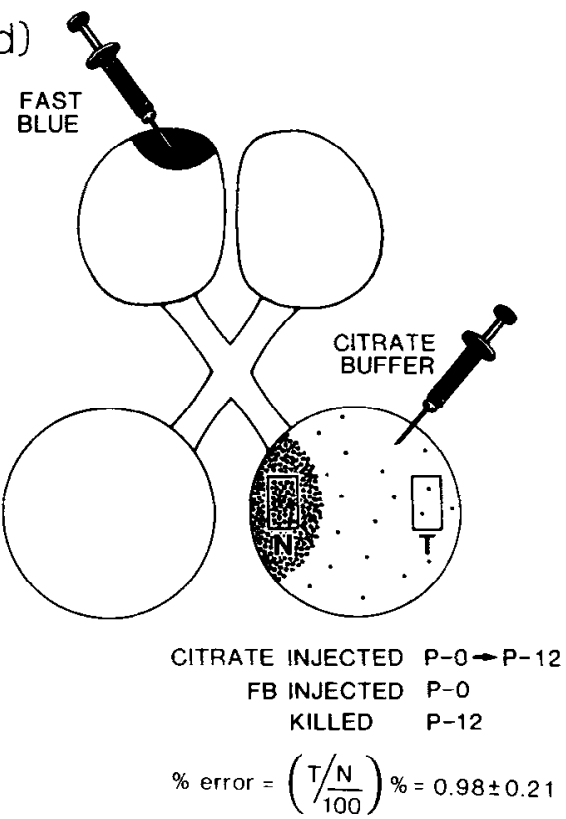

Figure 7. Diagrams illustrating the 4 experimental and control paradigms used to determine the role of ganglion cell activity in the elimination of cells that initially make longrange topographic targeting errors. In each case a small amount of FB was injected into the caudal part of the right superior colliculus at the times indicated, while either TTX or citrate buffer was injected into the left or right eye on alternate days (or in some cases every day) over the course of the experiment. The percentage error figures were calculated as before, from measurements of the labeled ganglion cell densities in the whole-mount preparations of the left retina. See Figure 2 and the text for further details. issue, in another group of experiments intraocular injections of TTX were made on alternate days between P0 and P14 (Fig. $7 b$ ), and on P12 a small injection $(0.025 \mu 1)$ of FB was made into the caudal part of the contralateral superior colliculus. The animals were perfused on P14. As before, areal measurements were made of the sectioned optic nerves, the locations of the FB injection sites were plotted, and the distribution of the labeled ganglion cells was determined in whole-mount preparations of the left retina. Twenty rats from this group survived the TTX injection regimen, and in 6 the optic nerves on the 2 sides had similar cross-sectional areas and the FB injections were correctly placed. To our surprise, the distribution of the labeled ganglion cells in these cases was found to be indistinguishable from that seen in normal rats injected with FB on P12 and killed on P14. In particular, there were relatively few labeled cells outside the primary, dense focus in the peripheral part of the nasal retina. As this finding was rather unexpected, we carried out a second series of experiments of this kind but made daily injections of TTX, injected the FB into the colliculus on $P 10$, and killed the animals on P12. Of the 10 rats in this group that survived the TTX injections, only 2 had optic nerves of similar sizes and appropriately placed FB injections. In both of these cases, the distribution of labeled ganglion cells was essentially the same as that seen in the previous group of experiments and in normal rats injected with FB at P12. As shown in Table 2 , when the data for the 2 groups of experiments were pooled, the percentage error was found to range from 0.00 to 2.56 , with a mean figure of $0.56 \pm 0.87$.

The findings in these 2 different experimental paradigms were complementary: Following TTX treatment, large numbers of 

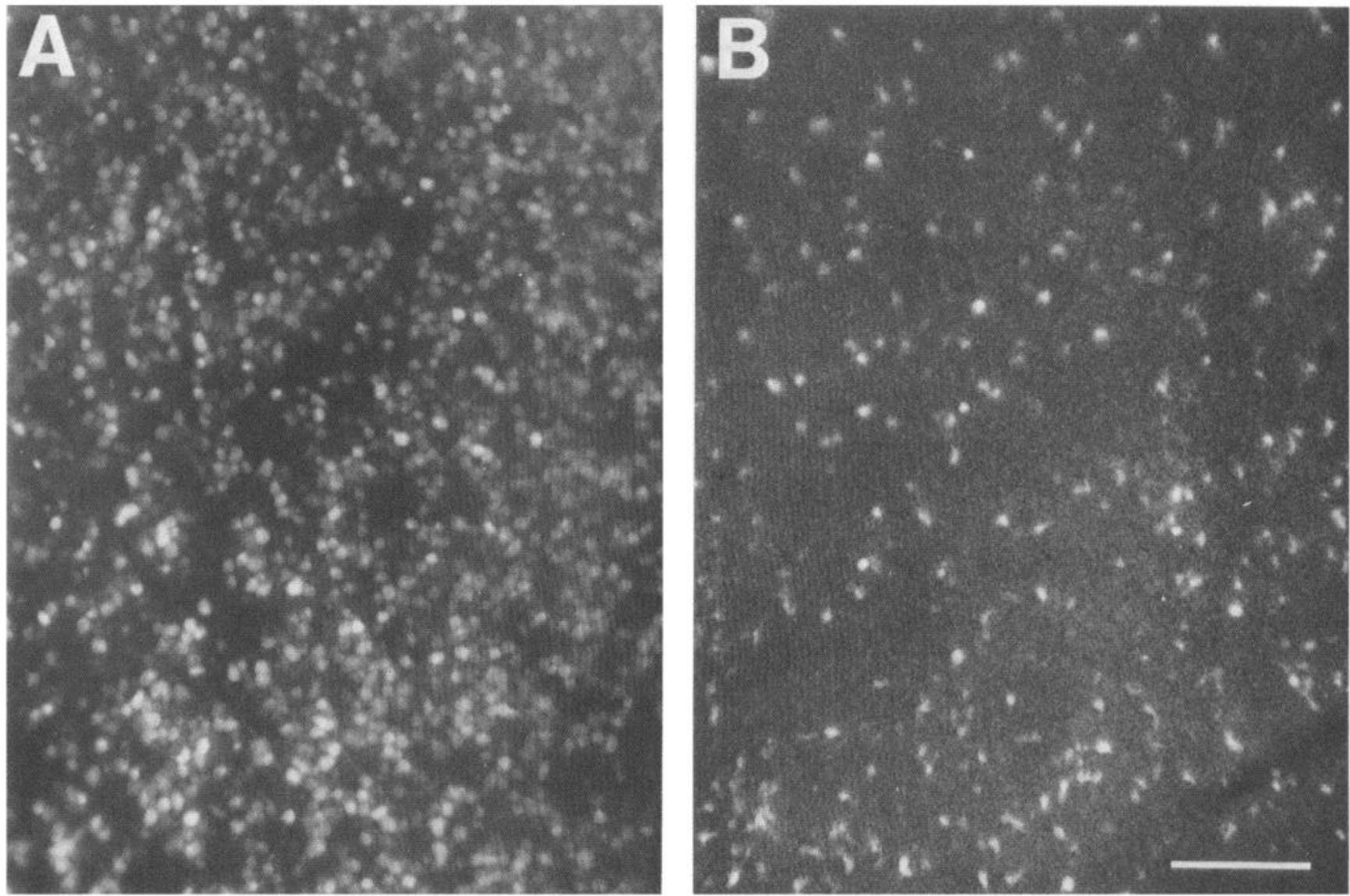

Figure 8. Fluorescence photomicrographs of a whole-mount preparation of the left retina from a P12 rat in which FB was injected into the caudal part of the right superior colliculus early on P0, and in which the left eye was injected with TTX on alternate days from P0 to P12. The density of labeled ganglion cells in the region of densest labeling in the peripheral part of the nasal retina $(A)$ appears to be comparable to that in normal P12 rats. However, an unusually high density of labeled ganglion cells is present in the temporal region of retina $(B)$. Indeed, the cell density in the temporal periphery is comparable to that found in rats injected with FB on P0 and killed about $30 \mathrm{hr}$ later. Scale bar, $250 \mu \mathrm{m}$.

labeled ganglion cells were seen outside the primary focus of labeling in the nasal periphery and throughout the temporal retina when the FB injection into the caudal part of the colliculus was made shortly after birth, but very few labeled ganglion cells were found outside the peripheral nasal retina when the injection was made on either P10 or P12. Taken together, the findings suggest that, although cells that project to inappropriate regions of the colliculus are not selectively eliminated when ganglion cell activity is blocked, by P10 their axons have withdrawn from at least the caudal part of the colliculus.

Controls for the TTX experiments. Two types of control experiments have been carried out (see Fig. $7, c, d$ ). In both, a localized injection of FB $(0.01 \mu \mathrm{l})$ was made into the caudal part of the right superior colliculus in the usual way. In 1 group of animals, TTX injections were made into the right (i.e., the ipsilateral) eye on alternate days, from P0 to P12; this was done to control for any general effects that intraocular TTX injections may have on the development of the retinocollicular projection. In the second group, citrate buffer (of the same concentration and at the same $\mathrm{pH}$ as that used to dissolve the TTX) was injected into the left (i.e., the contralateral) eye on alternate days, from P0 to P12. Both groups of rats were perfused on P12, and their brains, optic nerves, and retinas were prepared as before. Of the 26 animals in the first group, 8 were found to be suitable for analysis, as were 5 of the 10 citrate-buffer-treated rats. The distributions of the labeled ganglion cells in whole-mount preparations of the left retinas of both groups of animals were in- distinguishable from those seen in normal rats injected with FB on $\mathrm{P} 0$ and killed on $\mathrm{P} 12$, and the estimated percentage errors in the 2 groups were similarly comparable with those in normal animals (cf. Tables 1 and 2).

\section{Discussion}

The principal findings of this study can be summarized briefly. (1) If a small injection of FB is made into the caudal part of the superior colliculus on P12, i.e., immediately after the phase of naturally occurring ganglion cell death, very few labeled ganglion cells are found outside the primary focus of retrograde labeling in the periphery of the nasal retina of the contralateral side. On average, there is less than 1 labeled cell in the temporal retina for every 100 labeled cells in the corresponding part of the nasal retina. (2) If a comparable injection is made on the day of birth (early in the phase of naturally occurring ganglion cell death) and the animal is killed about $30 \mathrm{hr}$ later, the relative number of labeled ganglion cells in the temporal retina is approximately 35 times greater (about 14 for every 100 labeled cells in nasal retina); this implies that the axons of an appreciable proportion of the cells, instead of terminating near the rostral margin of the colliculus, have erroneously grown to its caudal pole. (3) When FB is injected on the day of birth and the animal is allowed to survive until just after the phase of naturally occurring ganglion cell death, there are, again, relatively few labeled cells in the temporal retina. This suggests, first, that the great majority of the early topographic targeting errors are elim- 
Table 2. Number of incorrectly projecting retinal ganglion cells/100 correctly projecting cells in each group of experimental rats

Inject TTX left eye $\mathrm{P} 0-\mathrm{P} 12$, inject fast

blue P0, kill P12

\begin{tabular}{ll}
\hline Case & Number \\
\hline TSC-4 $^{a}$ & 11.4 \\
TSC-2 $^{2}$ & 12.0 \\
TSC-9 $^{a}$ & 12.7 \\
TSC-3 $^{a}$ & 14.9 \\
TSC-8 $^{2}$ & 14.9 \\
TSC-13 & 17.2
\end{tabular}

Mean $\pm \mathrm{SD}=13.8 \pm 2.2$
Inject TTX left eye $\mathrm{P0}-$ $\mathrm{P} 12$, inject fast blue P10* or P12, kill P12* or P14

Case Number

TSC-23

TSC-25

TSC $-66^{a}$

TSC-68

TSC-79a.*

TSC-59

TSC-70*

TSC-24

Mean \pm SD $=0.56 \pm 0.87$
Inject TTX right eye $\mathrm{PO}-\mathrm{P} 12$, inject fast blue P0, kill P12

\begin{tabular}{|c|c|c|c|}
\hline & \\
\hline Case & Number & Case & Number \\
\hline TSC-17 & 0.39 & TSC-34a & 0.72 \\
\hline ISC-48 & 0.72 & TSC $-38^{a}$ & 0.88 \\
\hline TSC-46 & 0.86 & TSC-41 & 0.94 \\
\hline TSC-32 & 1.22 & TSC-35 & 1.10 \\
\hline TSC-80 & 1.25 & $\mathrm{TSC}-37^{\circ}$ & 1.27 \\
\hline TSC-33 & 1.37 & \multirow{3}{*}{\multicolumn{2}{|c|}{ Mean $\pm \mathrm{SD}=0.98 \pm 0.21$}} \\
\hline TSC-16 & 1.64 & & \\
\hline TSC-57 & 1.75 & & \\
\hline \multicolumn{4}{|c|}{ Mean $\pm \mathrm{SD}=1.15 \pm 0.46$} \\
\hline
\end{tabular}

"Actual counts of the numbers of axons in the 2 optic nerves were made from electron micrographs (see O'Leary et al., in press).

great majority of the early topographic targeting errors are eliminated during the phase of ganglion cell death and, second, that the elimination of these erroneous connections is due to the death of the parent cells. (4) Blocking impulse activity in the ganglion cells by intraocular injections of TTX throughout the period of naturally occurring ganglion cell death prevents the preferential elimination of the erroneously projecting cells but does not substantially reduce the overall amount of ganglion cell death (see O'Leary et al., 1986). (5) During TTX blockade, the misdirected axons seem to withdraw from the caudal part of the colliculus, even though their parent cells remain viable.

Although, by themselves, these findings are rather straightforward, there are a number of points that merit special discussion. Some of these follow.

The magnitude and nature of the topographic targeting errors. As our quantitative data refer only to the longest of the topographic targeting errors that occur, and since we have not attempted to determine the total number of labeled ganglion cells outside the primary focus in the nasal periphery, it is difficult to estimate just how many such errors occur. The total number is very likely in excess of the $12 \%$ calculated from our measurements of the relative cell densities in the nasal and temporal peripheries; if we were also to consider short-range topographic errors, the number might well represent a considerable proportion of the initial population of ganglion cells. (The $12 \%$ error rate in neonatal rats was determined by dividing the relative density of labeled cells in the temporal retina by the sum of the relative densities of labeled cells in the nasal retina and in the temporal retina, $\times 100$.)

By the nature of our experimental design, the errors assayed for in our study involve an overextension along the rostrocaudal axis of the colliculus. Ganglion cell axons that should terminate in the rostral part of the colliculus continue on to a region near its caudal pole. However, it is clear, especially in experiments in which the dye injection was displaced to one or the other side of the caudal colliculus, that errors also occur in the mediolateral dimension of the colliculus, possibly because the relevant axons enter it from an abnormal position within the optic tract (cf. Silver, 1984) or because they are misrouted as they grow through the stratum opticum.

Ganglion cell death and error correction. As we pointed out above, in the vertebrate nervous system, naturally occurring neuronal death is generally considered to be a mechanism for matching the size of each neuronal population to the needs of its primary target (for reviews, see Cowan and O'Leary, 1984; Cowan et al., 1984; Oppenheim and Hamburger, 1982; Purves, 1980). However, the present findings, when taken together with those of others who have examined the early development of the avian and mammalian visual systems (see the introduction), make it clear that cell death may play a second, but equally important, function, namely, to refine the initial patterns of connections laid down by selectively eliminating all, or at least most, of the neurons that make axonal targeting errors during development. In the case of retinofugal projections in rodents, it is clearly the principal (and probably the sole) mechanism responsible for the removal of the early retinoretinal projection seen during the first postnatal week (Bunt et al., 1983); for the progressive restriction of the ipsilateral retinocollicular projection (Insausti et al., 1984; Jeffrey and Perry, 1982; O'Leary et al., 1983a); for the elimination of topographic targeting errors within the superior colliculus, as shown here; and is likely to be responsible for the elimination of retinal axons misdirected to the inferior colliculus, the medial geniculate nucleus, and the ventrobasal complex (Frost, 1984).

It remains to be seen to what extent the massive death of retinal ganglion cells that occurs late in fetal life and during the first week or two postnatally [about $66 \%$ in rats (Crespo et al., 1985), and as much as $80 \%$ in kittens (Williams et al., 1986)] is attributable simply to the process of "systems matching," as defined by Rager (Rager and Rager, 1978), and to what extent it is due to error elimination. At present we do not have enough information to provide a reliable estimate of the relative importance of the 2 phenomena. Thus, whereas Sefton and Lam (1984) have suggested that up to $40 \%$ of the overall loss of retinal axons can be accounted for by the elimination of the retinoretinal projection, we have found that after intraocular injections of FB less than $1 \%$ of the ganglion cells are retrogradely labeled in the contralateral retina in neonates (D. D. M. O'Leary and R. Granich, unpublished observations). We have also tried to assess the number of ganglion cells that contribute to the early, exuberant ipsilateral retinocollicular projection, and our findings suggest that the restriction of this projection probably accounts for the death of no more than about 4000-5000 cellsless than $3 \%$ of the total number of ganglion cells lost (O'Leary, 1987). And, judging from the relatively small numbers of anterogradely labeled fibers that can be followed into the inferior colliculus or to the medial geniculate and ventrobasal nuclei (Frost, 1984), this type of error must, similarly, account for only a minute fraction of the ganglion cells that die. We have not attempted to count the total number of ganglion cells that project to inappropriate regions of the colliculus, but it is likely that their number is appreciably in excess of the percentage error calculated from our temporal-vs-nasal cell density estimates. Whatever the actual number of topographic targeting errors may 
be, the essential finding in our experiments is that $91-97 \%$ of the cells that make long-range errors of this type die. ${ }^{1}$ And if we accept the percentage error rate determined in this study as a representative figure for all regions of retina, then the elimination of this class of error alone could well account for $20 \%$ or more of the total amount of ganglion cell loss.

The mechanism responsible for the elimination of early targeting errors. The finding that only about $3-9 \%$ of the ganglion cells in the temporal retina labeled by a FB injection into the caudal colliculus on $\mathrm{P} 0$ are recognizable by the $\mathrm{P} 12^{1}$ provides the most direct evidence that erroneously projecting ganglion cells die. And it is significant that the period during which they are eliminated coincides with the major phase of cell loss within the ganglion cell population as a whole, during which about $60 \%$ of the initial population of ganglion cells degenerates (Crespo et al., 1985; Lam et al., 1982; Perry et al., 1983). Similar longterm labeling experiments also suggest that, if collateral elimination plays a role in the removal of long-range targeting errors, its role is a minor one at best. In this sense, the refining of the retinocollicular projection is quite different from the postnatal reorganization that occurs in certain other systems. For example, the dramatic changes that occur postnatally in the organization of the callosal and corticospinal systems are brought about by the selective removal of particular axon collaterals, apparently without the death of a significant proportion of the relevant neurons (Innocenti, 1981; Ivy and Killackey, 1982; O'Leary and Stanfield, 1986; O'Leary et al., 1981; Stanfield et al., 1982). However, it is important to emphasize that in concluding that cell death is the principal factor responsible for the refinement of the retinocollicular projection, we are referring only to the long-range targeting errors that our experiments were designed to reveal. A different mechanism might well account for the short-range refinements that almost certainly take place. Inappropriate short branches of retinal axons may well be selectively eliminated or relocated without the death of the parent ganglion cell.

The fact that, on average, only about $3-9 \%$ of the cells that make erroneous connections survive beyond the $\mathrm{P} 12^{1}$, whereas as much as $40 \%$ of the overall ganglion cell population survives, suggests that cells whose axons project to inappropriate loci are preferentially eliminated, and that, while they are removed during the general phase of ganglion cell death, there is a mechanism that specifically selects against them. We have elsewhere (Cowan et al., 1984; Fawcett and O'Leary, 1985) suggested a possible mechanism for the preferential elimination of cells with aberrant axons which, in its most general form, is similar to that originally postulated by Hebb (1949) as a cellular mechanism for learning and elaborated upon by Stent (1973) to account for some of the effects of selective visual deprivation. Our hypothesis rests on 3 plausible assumptions: first, that the axons of the erroneously projecting ganglion cells compete with their neighbors, which have made the correct connections, for an essential trophic factor that is available only in limited amounts within the colliculus; second, that the release of the trophic material is regulated in some way by activity - for example, by an appropriate level of depolarization of collicular neurons (or by the consequent depolarization of the surrounding glial cells); and third, that neighboring ganglion cells are more likely to fire synchronously

\footnotetext{
1 These figures were calculated from the mean percentage error data obtained from normal rats injected on $\mathrm{P} 0$ and killed on $\mathrm{P} 1 / \mathrm{P} 2$ and from the normal, longterm cases injected on P0 and killed on P12 (Table 1). If one were to assume that there was no loss of correctly projecting ganglion cells, it would appear that about $9 \%$ of the ganglion cells that are labeled in the temporal retina after a FB injection on P0 would be present on P12. However, if we allow that about $60 \%$ of the correctly projecting ganglion cells die, then as little as $3 \%$ of the cells labeled in the temporal retina would survive.
}

than are nonneighboring cells. ${ }^{2}$ Under these circumstances, the axons of neighboring ganglion cells, which project to the same region and have made the correct connections, will have a competitive advantage over isolated axons from remote regions of the retina in at least 2 respects-their correlated firing should result in the release of larger amounts of the relevant trophic factor, and their terminals should be actively recycling synaptic vesicle membrane (and consequently taking up materials from the surrounding spaces; Heuser and Reese, 1973) at the very time the released trophic material becomes available. The random firing of an isolated, misplaced axon might also induce the release of some of the trophic material (unless the level of depolarization is insufficient or the target cell's stores are depleted), but in most cases this will probably be insufficient to meet the needs of its parent cell.

If this hypothesis is valid, at least in broad outline, it would provide an explanation for the findings in our TTX experiments that, when activity is blocked, the competitive advantage of neighboring, correctly projecting ganglion cells is minimized and the cells with aberrant axons have an equal chance of survival. Our findings also suggest 2 important corollaries. The first is that the relevant trophic factors must be constitutively released at some level which, even in the absence of impulse activity in retinal axons, is sufficient to maintain a substantial proportion (at least a third) of the ganglion cells and their axons. And second, it is clear that axon terminals need not be active (in the sense of being invaded by nerve impulses) in order to take up trophic materials and to transport them back to their cell bodies retrogradely. Only if these 2 additional assumptions arc madc can we account for the survival of both correctly projecting ganglion cells and those whose axons have made targeting errors when their activity is blocked by intraocular TTX injections. For, under these circumstances, not only does a near-normal amount of ganglion cell death occur over the same time period as in untreated animals (O'Leary et al., 1986), but there is also no indication that the cells with misdirected axons are selectively eliminated. On the contrary, they seem to be affected in rougly the same proportion as the general ganglion cell population, that is, ganglion cell death appears to be randomized when activity is blocked with TTX.

It is more difficult to account for the findings in our later experiments, in which FB was injected into the colliculus either at the time TTX injections into the contralateral eye were initiated or just before the animals were killed. Together, these 2 groups of experiments indicate that the cells that make topographic targeting errors do not all die, yet do retract their axons from the caudal part of the colliculus. It is conceivable that this retraction of the misdirected axons is preparatory to their delayed death, but, more likely, we can ascribe some of the removal of these long-range errors to a nonspecific contraction in the size of the optic fiber terminals during the first days of postnatal life (Schneider et al., 1981). At least in the regenerating fish retinotectal projection, some terminal arbor contraction occurs even in the presence of a TTX blockade (J. T. Schmidt, personal communication), although the retraction may be around an incorrect locus (Schmidt and Edwards, 1983). It is also likely that terminal arbor remodeling may be influenced by non-activity-related factors, such as the matching of positional addresses between retina and colliculus (see, for example, Smalheiser and Crain, 1984). Such factors may be important in the

\footnotetext{
${ }^{2}$ Although the intraretinal circuity involved in relaying information from the photoreceptors to the ganglion cells is not fully assembled and functional until about P12 (Weidman and Kuwabara, 1968), the ganglion cells are known to be spontaneously active during the first 2 weeks postnatally (Lipton and Harcourt, 1984). And while there is no direct evidence for the coincident spontaneous firing of neighboring ganglion cells in rats, it has been well established in other species (Amett, 1978; Ginsberg et al., 1984; Mastronarde, 1983a-c).
} 
removal of incorrectly projecting retinotectal axons in the chick, which apparently can be removed from regions of tectum that are devoid of correctly targeted axons (McLoon, 1982). As we have discussed elsewhere (Cowan et al., 1984), one of the attractions of the "trophic factor hypothesis" is that it can account for both the survival and/or death of neurons, and also for the selective loss of processes; to this extent, it has the merit of parsimony (see also Campenot, 1982a, b). We use the term "retraction" advisedly, since we do not wish to imply that the axons relocate to the correct topographic region of the colliculus. In fish and some amphibians there is, in fact, good evidence for the withdrawal and redeployment of axonal arbors within the optic tectum, both during normal development and after various cxpcrimental manipulations (for a review, see Easter, 1983; Levine, 1984; Sharma and Romeskie, 1984), but at present there is no convincing evidence for the relocation of terminal arbors in the mammalian brain, although there are many instances of exuberant terminal arbors and short side branches being pared down (LeVay and Stryker, 1978; Schneider et al., 1981; Sretavan and Shatz, 1986).

Finally, we should point out that, although the fast axonal transport of ${ }^{3} \mathrm{H}$-proline-labeled proteins appears to be unaffected by TTX, there is evidence that intraocular injections of TTX result in a significant reduction in the rapid transport of ${ }^{3} \mathrm{H}$-fucose-labeled glycoproteins along the optic nerves of rats during the second and third postnatal weeks (Riccio and Matthews, 1985), and also of goldfish (Edwards and Grafstein, 1984). It seems likely that a generalized effect of this kind could prevent the selective elimination of the topographically incorrectly projecting ganglion cells that we have observed or, for that matter, any of the other connectional refinements that appear to be activity-related (for a review, see Constantine-Paton, 1983; Fawcett and O'Leary, 1985; Thompson, 1985; Udin, 1985). The notion that the relative correlation of patterns of activity among axons is a driving force behind these events is strongly supported by numerous recent studies (for a review, see Schmidt, 1985; Schmidt and Tieman, 1985). Among these findings, we may mention the refinement of the regenerated retinotectal projection in goldfish, which can be prevented by intraocular injections of TTX (Meyer, 1983; Schmidt and Edwards, 1983) and also by raising the animals under stroboscopic illumination (Schmidt and Eisele, 1985), both of which effectively eliminate the natural asynchrony between spatially separated ganglion cells. Similarly, Stryker and his colleagues have found that the normal segregation of geniculocortical axons into ocular dominance stripes in layer IV of area 17 in kittens can be prevented by bilateral intraocular injections of TTX (Stryker and Harris, 1986). Further, ocular dominance stripes do not develop if the optic nerves from the TTX-injected eyes are synchronously stimulated artificially; only if the 2 optic nerves are asynchronously activated do the geniculocortical axons segregate in a more-or-less normal fashion (Stryker and Strickland, 1984).

\section{References}

Arnett, D. W. (1978) Statistical dependence between neighboring retinal ganglion cells in the goldfish. Exp. Brain Res. 32: 49-53.

Bentivoglio, M., H. G. J. M. Kuypers, C. E. Catsman-Berrevoets, and O. Dann (1979) Fluorescent retrograde neuronal labeling in rat by means of substances binding specifically to adenine-thymine rich DNA. Neurosci. Lett. 12: 235-240.

Bentivoglio, M., H. G. J. M. Kuypers, C. E. Catsman-Berrevoets, H. Loewe, and O. Dann (1980) Two new fluorescent retrograde neuronal tracers which are transported over long distances. Neurosci. Lett. 18: 25-30.

Bunt, S. M., R. D. Lund, and P. W. Land (1983) Prenatal development of the optic projection in albino and hooded rats. Dev. Brain Res. 6 : 149-168.

Campenot, R. B. (1982a) Development of sympathetic neurons in compartmentalized cultures. I. Local control of neurite growth by nerve growth factor. Dev. Biol. 93: 1-12.
Campenot, R. B. (1982b) Development of sympathetic neurons in compartmentalized cultures. II. Local control of neurite survival by nerve growth factor. Dev. Biol. 93: 13-21.

Clarke, P. G. H. (1981) Chance, repetition, and error in the development of normal nervous systems. Perspect. Biol. Med. 25: 2-19.

Clarke, P. G. H., and W. M. Cowan (1976) The development of the isthmo-optic tract in the chick, with special reference to the occurrence and correction of developmental errors in the location and connections of isthmo-optic neurons. J. Comp. Neurol. 167: 143-164.

Constantine-Paton, M. (1983) Position and proximity in the development of maps and stripes. Trends Neurosci. 6: 32-36.

Cowan, W. M., and D. D. M. O'Leary (1984) Cell death and process elimination: The role of regressive phenomena in the development of the vertebrate nervous system. In Medicine, Science, and Society: Symposia Celebrating the Harvard Medical School Bicentennial, K. J. Isselbacher, ed., pp. 643-668, Wiley, New York.

Cowan, W. M., J. W. Fawcett, D. D. M. O'Leary, and B. B. Stanfield (1984) Regressive events in neurogenesis. Science 225: 1258-1265.

Crandall, J. E., J. M. Whitcomb, and V. S. Caviness, Jr. (1985) Development of the spino-medullary projection from the mouse banel field. J. Comp. Neurol. 239: 205-215.

Crespo, D., D. D. M. O'Leary, and W. M. Cowan (1985) Changes in the numbers of optic nerve axons during late prenatal and early postnatal development of the albino rat. Dev. Brain Res. 19: 129-134.

Dubin, M. W., L. A. Stark, and S. M. Archer (1986) A role for actionpotential activity in the development of neuronal connections in the kitten retinogeniculate pathway. J. Neurosci. 6: 1021-1036.

Easter, S. S., Jr. (1983) Postnatal neurogenesis and changing connections. Trends Neurosci. 6: 53-56.

Edwards, D. L., and B. Grafstein (1984) Intraocular injection of tetrodotoxin in goldfish decreases fast axonal transport of $\left[{ }^{3} \mathrm{H}\right]$ glucosamine-labeled materials in optic axons. Brain Res. 299: 190-194.

Fawcett, J. W., and D. D. M. O'Leary (1985) The role of electrical activity in the formation of topographic maps. Trends Neurosci. 8 : 201-206.

Fawcett, J. W., D. D. M. O'Leary, and W. M. Cowan (1984) Activity and the control of ganglion cell death in the rat retina. Proc. Natl. Acad. Sci. USA 80: 6131-6135.

Frost, D. O. (1984) Axonal growth and target selection during development: Retinal projections to the ventrobasal complex and other "nonvisual" structures in neonatal Syrian hamsters. J. Comp. Neurol. 230: 576-592.

Frost, D. O., and G. E. Schneider (1979) Postnatal development of retinal projections in Syrian hamsters: A study using autoradiographic and anterograde degeneration techniques. Neuroscience 4: 1649-1677.

Ginsburg, K. S., J. A. Johnsen, and M. W. Levine (1984) Common noise in the firing of neighboring ganglion cells in goldfish retina. $J$. Physiol. (Lond.) 351: 433-451.

Godement, P., J. Salaun, and M. Imbert (1984) Prenatal and postnatal development of retinogeniculate and retinocollicular projections in the mouse. J. Comp. Neurol. 230: 552-575.

Hamburger, V., and R. W. Oppenheim (1982) Naturally occurring neuronal death in vertebrates. Neurosci. Comm. 1: 39-55.

Hebb, D. O. (1949) Organization of Behavior, Wiley, New York.

Hubel, D. H. (1957) Tungsten microelectrode for recording from single units. Science 125: 549-550.

Hueser, J. E., and T. S. Reese (1973) Evidence for recycling of synaptic membrane during transmitter release at the frog neuromuscular junction. J. Cell Biol. 57: 315-344.

Innocenti, G. M. (1981) Growth and reshaping of axons in the establishment of visual callosal connections. Science 212: 824-827.

Insausti, R., C. Blakemore, and W. M. Cowan (1984) Ganglion cell death during development of ipsilateral retinocollicular projection in golden hamster. Nature 308: 362-365.

Insausti, R., C. Blakemore, and W. M. Cowan (1985) Postnatal development of the ipsilateral retinocollicular projection and the effects of unilateral enucleation in the golden hamster. J. Comp. Neurol. 234: 393-409.

Ivy, G. O., and H. P. Killackey (1982) Ontogenetic changes in the projections of neocortical neurons. J. Neurosci. 2: 735-743.

Jeffrey, G., and V. H. Perry (1982) Evidence for ganglion cell death during development of the ipsilateral retinal projection in the rat. Dev. Brain Res. 2: 176-180.

Lam, K., A. J. Sefton, and M. R. Bennett (1982) Loss of axons from the optic nerve of the rat during early postnatal development. Dev. Brain Res. 3: 487-491. 
I and, P. W., and R. D. Lund (1979) Development of the rat's uncrossed retinotectal pathway and its relationship to plasticity studies. Science 105: 698-700.

LeVay, S., and M. P. Stryker (1978) The development of ocular dominance columns in the cat. In Aspects of Developmental Neurobiology, J. Ferendelli, ed., pp. 83-98, Society for Neuroscience, Bethesda, MD.

Levine, R. L. (1984) Neuronal plasticity in the optic tectum of amphibians. In Comparative Neurology of the Optic Tectum, H. Vanegas, ed., pp. 495-545, Plenum, New York.

Linden, R., and V. H. Perry (1983) Massive retinotectal projection in rats. Brain Res. 272: 145-149.

Lipton, S. A., and P. Harcourt (1984) The effect of tetrodotoxin on the death of mammalian retinal ganglion cells. Soc. Neurosci. Abstr. 10: 1081 .

Mastronarde, D. N. (1983a) Correlated firing of cat retinal ganglion cells. I. Spontaneously active inputs to $X$ - and $Y$-cells. J. Neurophysiol. 49 : 303-324

Mastronarde, D. N. (1983b) Correlated firing of cat retinal ganglion cells. II. Responses of X-and Y-cells to single quantal events. J. Neurophysiol. 49: 325-349.

Mastronarde, D. N. (1983c) Interactions between ganglion cells in cat retina. J. Neurophysiol. 49: 350-365.

McLoon, S. C. (1982) Alterations in precision of the crossed retinotectal projection during chick development. Science 215: 1418-1420.

McLoon, S. C., and R. D. Lund (1982) Transient retinofugal pathways in the developing chick. Exp. Brain Res. 45: 277-284.

Meyer, R. L. (1983) Tetrodotoxin inhibits the formation of refined retinotopography in goldfish. Dev. Brain Res. 6: 293-298.

Morest, D. K. (1970) The pattern of neurogenesis in the retina of the rat. Z. Anat. Entwickl. Gesch. 131: 45-67.

O'Leary, D. D. M. (1987) The remodeling of early axonal projections through the selective loss of neurons and axon collaterals. In Selective Neuronal Death (Ciba Foundation Symposium No. 126), O'Connor, ed., pp. 113-142, Wiley, Chichester, UK.

O'Leary, D. D. M., and W. M. Cuwan (1982) Further sludies on the development of the isthmo-optic nucleus with special reference to the occurrence and rate of ectopic and ipsilaterally projecting neurons. J. Comp. Neurol. 212: 399-416.

O'Leary, D. D. M., and B. B. Stanfield (1986) A transient pyramidal tract projection from the visual cortex in the hamster and its removal by selective collateral elimination. Dev. Brain Res. 27: 87-99.

O'Leary, D. D. M., and S. Thanos (1985) A transient retinofugal pathway in the chick embryo and its possible role in the guidance of axons to the retina. Anat. Rec. 211: 142A.

O'Leary, D. D. M., B. B. Stanfield, and W. M. Cowan (1981) Evidence that the early postnatal restriction of the cells of origin of the callosal projection is due to the elimination of axonal collaterals rather than to the death of neurons. Dev. Brain Res. 1: 607-617.

O'Leary, D. D. M., J. W. Fawcett, and W. M. Cowan (1983a) The early postnatal restriction of the ipsilateral retinocollicular projection is due to cell death rather than collateral elimination. Soc. Neurosci. Abstr. 9: 856.

O'Leary, D. D. M., C. R. Gerfen, and W. M. Cowan (1983b) The development and restriction of the ipsilateral retinofugal projection in the chick. Dev. Brain Res. 10: 93-109.

O'Leary, D. D. M., J. W. Fawcett, and W. M. Cowan (1984) Elimination of topographical targeting errors in the retinocollicular projection by ganglion cell death. Soc. Neurosci. Abstr. 10: 464.

O'Leary, D. D. M., D. Crespo, J. W. Fawcett, and W. M. Cowan (1986) The effect of intraocular tetrodotoxin on the postnatal reduction in the numbers of optic nerve axons in the rat. Dev. Brain Res. (in press).

Oppenheim, R. W. (1981) Neuronal cell death and some related regressive phenomena during neurogenesis: A selective historical review and progress report. In Studies in Developmental Neurobiology: Essays in Honor of Viktor Hamburger, W. M. Cowan, ed., pp. 74-133, Oxford U. P., New York.

Oppenheim, R. W., and V. Hamburger (1982) Naturally occurring neuronal death in vertebrates. Neurosci. Comment. 1: 39-55.

Perry, V. H., Z. Henderson, and R. Linden (1983) Postnatal changes in retinal ganglion cell and optic axon populations in the pigmented rat. J. Comp. Neurol. 219: 356-368.

Price, D. J., and C. Blakemore (1985) The postnatal development of the association projection from visual cortical area 17 to area 18 in the cat. J. Neurosci. 5: 2443-2452.

Purves, D. (1980) Neuronal competition. Nature 287: 585-586.
Rager, G., and U. Rager (1978) Systems matching by degeneration. I. A quantitative electron microscopic study of the generation and degeneration of ganglion cells in the chicken. Exp. Brain Res. 33: 6578.

Riccio, R. V., and M. A. Matthews (1985) The effect of intraocular injection of tetrodotoxin on fast axonal transport of $\left[{ }^{3} \mathrm{H}\right]$ proline- and $\left[{ }^{3} \mathrm{H}\right]$ fucose-labeled materials in the developing rat optic nerve. Neuroscience 16: 1027-1039.

Sawchenko, P. E., and L. W. Swanson (1981) A method for tracing biochemically defined pathways in the central nervous system using combined fluorescence retrograde transport and immunohistochemical techniques. Brain Res. 210: 31-51.

Schmidt, J. T. (1985) Formation of retinotopic connections: Selective stabilization by an activity-dependent mechanism. Cell. Mol. Neurobiol. 5: 65-84.

Schmidt, J. T., and D. L. Edwards (1983) Activity sharpens the map during the regeneration of the retinotectal projection in goldfish. Brain Res. 269: 29-39.

Schmidt, J. T., and L. E. Eisele (1985) Stroboscopic illumination and dark rearing block the sharpening of the regenerated retinotectal map in goldfish. Neuroscience 14: 535-546.

Schmidt, J. T., and S. B. Tieman (1985) Eye-specific segregation of optic afferents in mammals, fish, and frogs: The role of activity. Cell. Mol. Neurobiol. 5: 5-34.

Schneider, G. E., L. Rava, G. M. Sachs, and S. Jhaveri (1981) Widespread branching of retinotectal axons: Transient in normal development and anomalous in adults with neonatal lesions. Soc. Neurosci. Abstr. 7: 732 .

Sefton, A. J., and K. Lam (1984) Quantitative and morphological studies on developing optic axons in normal and enucleated albino rats. Exp. Brain Res. 57: 107-1 17.

Sharma, S. C., and M. Romeskie (1984) Plasticity of retinotectal connections in teleosts. In Comparative Neurology of the Optic Tectum, H. Vanegas, ed., pp. 163-184, Plenum, New York.

Silver, J. (1984) Studies on the factors that govern directionality of axonal growth in the embryonic optic nerve and at the chiasm of mice. J. Comp. Neurol. 223: 238-251.

Siminoff, R., H. O. Schwassmann, and L. Kruger (1966) An electrophysiological study of the visual projection to the superior colliculus of the rat. J. Comp. Neurol. 127: 435-444.

Smalheiser, N. R., and S. M. Crain (1984) The possible role of "sibling neurite bias" in the coordination of neurite extension, branching, and survival. J. Neurobiol. 15: 517-529.

Sretavan, D. W., and C. J. Shatz (1986) Prenatal development of retinal ganglion cell axons: Segregation into eye-specific layers within the cat's lateral geniculate nucleus. J. Neurosci. 6: 234-251.

Stanfield, B. B., and D. D. M. O'Leary (1985) The transient corticospinal projection from the visual cortex during the postnatal development of the rat. J. Comp. Neurol. 238: 236-248.

Stanfield, B. B., D. D. M. O'Leary, and C. Fricks (1982) Selective collateral elimination in early postnatal development restricts cortical distribution of rat pyramidal tract neurones. Nature 298: 371-373.

Stent, G. S. (1973) A physiological mechanism for Hebb's postulate of learning. Proc. Natl. Acad. Sci. USA 70: 997-1001.

Stryker, M. P., and W. A. Harris (1986) Binocular impulse blockade prevents the formation of ocular dominance columns in cat visual cortex. J. Neurosci. 6: 2117-2133.

Stryker, M. P., and S. L. Strickland (1984) Physiological segregation of ocular dominance columns depends on the pattern of afferent electrical activity. Invest. Ophthalmol. Vis. Sci. 25: 278

Thanos, S., and F. Bonhoeffer (1984) Development of the transient ipsilateral retinotectal projection in the chick embryo: A numerical fluorescence-microscopic analysis. J. Comp. Neurol. 224: 407-414.

Thompson, W. J. (1985) Activity and synapse elimination at the neuromuscular junction. Cell. Mol. Neurobiol. 5: 167-182.

Udin, S. B. (1985) The role of visual experience in the formation of binocular projections in frogs. Cell. Mol. Neurobiol. 5: 85-102.

Weidman, T. A., and T. Kuwabara (1968) Postnatal development of the rat retina. An electron microscopic study. Arch. Ophthalmol. 79: $470-484$.

Williams, R. W., M. J. Bastiani, B. Lia, and L. M. Chalupa (1985) Growth cones, dying axons, and developmental fluctuations in the fiber population of the cat's optic nerve. J. Comp. Neurol. 246: 3269. 